\section{Clinical Guidelines and the Law: Negligence, Discretion and Judgment}

\author{
Brian Hurwitz, Oxford, Radcliffe \\ Medical Press, 1998, 134 pages, \\ $£ 18.50$ (s b).
}

This book could not be more timely. The white paper,' which will lead to the establishment of clinical governance, national framework standards, and the promotion of clinical excellence through a national institute, presents a challenge to the clinical judgment and clinical freedom of the doctor. Not that the issue of the status of clinical guidelines in relation to the clinical judgment and freedom of the doctor is new. As the author points out, it was a subject of concern to Plato, who explored with his students the difference between skills grounded in practical expertise and those based merely upon instruction or obeying rules.

The book is extensively researched and referenced and covers in six short chapters topics relating to: the nature and context of clinical guidance; the authority and validity of clinical guidelines; the legal status of clinical guidelines; clinical guidelines and negligence case law; author liability and clinical discretion, and clinical judgment and clinical freedom. Appendices give fuller details of some of the key cases, and there is a synopsis of significant articles taken from the UK, the Commonwealth and the USA. A foreword by Sir Douglas Black emphasises the importance of the topic. This is a readable and enlightening book, well illustrated by examples from clinical practice, thought-provoking, clear, and comprehensive. For clarity, the main points are summarised at the end of each chapter.

The author explains clearly and with authority the varied ways in which protocols, procedures, practices, and guidelines come into existence. He says 5,000 statements are issued annually by the National Health Service (NHS) executive and other health service agencies, consisting of guidance, executive letters and official instructions. To these must be added the textbooks and articles from medical researchers on appropriate clinical practice. Not all clinical guidelines should be approved and the author lists ten key characteristics which they should possess to be acceptable. He could perhaps have added ethical acceptability to these. Appropriate examples are given of the establishment of clinical guidelines and their variety, and the circumstances in which they may be ignored.

In reviewing the legal status of clinical guidelines in the UK he shows that the Bolam test, albeit battered and refined by the Bolitho case, ensures that clinical judgment is still protected if it is in accordance with reasonable competent practice. A doctor is not negligent just because he/she has not followed a guideline, but conversely he/she may be negligent if he/she has followed a guideline without relevance to the particular circumstances of the patient. However, as guidelineinformed health care increasingly becomes customary, there will be more pressure for the doctor who acts outside guidelines to prove justification from the specific circumstances of the case.

The author also considers the liability of the authors and propagators of clinical guidelines, concluding that if they suggest the advice they give should not be adopted "without independent inquiry" then this might act as a sufficient disclaimer in the event of any action for negligence.

The book should become compulsory reading for all those whose task it will be, in the post- white-paper era, to implement the effect of the results from clinical effectiveness studies, national framework standards and the work of the Commission for Health Improvements. Thus health service managers, contractors, providers, and professionals drawing up protocols should be familiar with the complexity of the subject and the dangers. The book will not provide the answers, but it will ensure that the draughtsmen realise the significance in both law and practice of the protocols and procedures which they design. Expert witnesses in the period following the Woolf reforms should also be familiar with this book and be hesitant to condemn practice for the sole reason that the usual guidelines were not followed.

Doctors will never become robots. Medicine will always be both an art and a science and clinical freedom to ensure that the individual patient is given the appropriate treatment for his personal needs is essential. At the same time, the patient must be protected from unacceptable practice, such as that recently seen in Bristol in the provision of paediatric cardiac surgery. The dangers of health care prac- tice being dominated by the rules and regulations of managers, insurance companies and other purchasers can be seen vividly in the work of Joan Brady. $^{2}$

The book proposes no solutions: that is not its aim. However, it provides a valuable, informed contribution to the debate which will be continuing for centuries to come.

\section{References}

1 Department of Health. The new NHS: modern $\bullet$ dependable. London: Stationery Office, Dec 1997.

2 Brady J. Death comes for Peter Pan. London: Minerva, 1997.

BRIDGIT DIMOND

Emeritus Professor, University of Glamorgan

\section{A Chosen Death: The Dying Confront Assisted Suicide}

\section{Shavelson, Berkeley, University of California Press, 1998, 244 pages, US\$14.95.}

Throughout the 1990s euthanasia and physician-assisted suicide have been the subject of hot debate by the general public as well as the professional press, by the legal fraternity as well as the medical colleges. But the 1990s have also seen a widespread espousal of the hospice philosophy and better palliative care. If the management of dying is receiving so much attention why do terminally ill patients still end their lives with plastic bags over their heads? Why do relatives still risk imprisonment to assist their dying at a time of their choosing? The author of $A$ Chosen Death, Lonny Shavelson, argues that today in the USA at least, such patients "face a medical system filled with secrecy, contradictions, contentious debate, and at times outright hypocrisy. If the public is concerned about the unfairness and abuses that may occur if assisted suicide and euthanasia were made legal, they might well look at the system as it is working now." This is precisely what he sets out to do.

This book, however, is no academic treatise on the ethics of ending lives. Shavelson himself is a doctor and a journalist with excellent personal credentials for writing on this subject. When he was just 14 years old his mother, severely depressed and bedridden with Crohn's disease, begged him to give her a fatal injection of potassium chloride. And his postscript 
recounts the agony and the challenge of being with his father who lay for hours "sweating, gasping for breath, gurgling - but not dying" after lifeprolonging procedures were withdrawn. In between these two major events, he struggled to unravel the issues inherent in helping patients to die. To facilitate the process he entered into the lives of people who were actually confronting the question of suicide - by their own hand or with assistance - when life became intolerable. Quite deliberately he became personally engaged in their struggle, lived alongside them in their search for an answer. He shared their last hours, witnessed others assisting their deaths, was challenged to assist himself.

The resulting book does not shirk the difficult questions; it does not sanitise the pain. In short it deals with real life ethics rather than the theoretical. Indeed, the grainy photographs accompanying the text somehow underline the reality of these situations like snaps taken to capture precious moments with a friend. It looks at the reality of such situations: the difficulty of deciding whether it is simply depression speaking when a patient asks for death; when such a request is premature. It describes at first hand the horror of failed efforts at suicide or attempts to assist a death only to have the patient fighting to live at the eleventh hour. It recognises the potential for abuse in physician-assisted suicide and the problems of building in adequate safeguards.

Shavelson concludes that the present system fails the terminally ill and the severely disabled. The very fact that so many patients are seeking suicide demonstrates its inadequacy. The lengths to which these people are prepared to go underlines the urgency of the need to provide for their end. But when provision rests with the patient or his/her family, there is a great potential for disaster, guilt and legal repercussions. And it is a disaster if a person reaches a point where he has gone through the whole process of suicide - the decision and the act - and it fails. Furthermore, suicide excludes those too weak or disabled to take matters into their own hands. The author concludes that having a professional take charge would seem so much more humane and reliable. $\mathrm{He}$ therefore examines a compromise course: the proposal that doctors should prescribe lethal doses of drugs like Seconal to ensure a more certain death. He ends with a consideration of a blend of "Hospice and Hemlock," a development which requires modification of the law but which offers protection for doctor and patient.

Although this is a book which will appeal to people from all walks of life, Shavelson directs certain challenges straight at his medical colleagues. The profession, he contends, "appears to turn its back on these horrible moments (during the last stages of illnesses) in order to keep its intentions pure". He forces the clinician to turn around and face the issue foursquare.

No thinking person can fail to be moved by this slim volume but some serious students might well be irritated by small deficiencies such as loose referencing, the absence of an index, the use of terms which confound rather than clarify. Others will find the text strangely jarring in places where the thought processes of the author and the reader take them in different directions. But the strengths of the book far outweigh its weal nesses, with challenges as relevant in the UK as they are in the USA.

As he sat with a dying friend ove्दु whose head he had himself slipped $\vec{z}$ black plastic bag, Shavelson admits to a great sense of loneliness. But he w隽. not really alone, he was "with hurs dreds of other families who have face $\mathbf{\Omega}$ the anguish of similar dilemmas, i⿱ hiding, inexperienced and without adequate guidance ... forced to decide? and to act, alone". Together the arrived at "one common thoughw That this is not how it should be." Fo각 anyone who will hear this cry, anyono who will accept the inadequacy of this present system, this book makes sobering and compelling reading.

HAZEL E MCHAFFI Research Fellow, Medical Ethics, University o Edinburgh and Deputy Director of Research, Institute of Medical Ethics

\section{Books: information and orders}

If you wish to order or require furbe information regarding the tides viewed here, please write to or phone the BMJ Bookshop, PO 295, London WC1H 9JR. Tel: 017థ 383 6244. Fax: 0171383 6662. Bool are supplied post free in the UK and for BFPO addresses. Overseas customers should add 15 per cent fo postage and packing. Payment can be made by cheque in sterling drawn on $\bar{P}$ UK bank or by credit card (Mastero card, Visa, or American Express, sta ing card number, expiry date, and fu name (The price and availability are occasionally subject to revision by the publishers). 